\title{
A/r/tografía Social y Educación Artística para la Justicia Social: Proyecto BombeArte
}

\section{Social A/r/tography and Art Education for Social Justice: BombeArte Project}

Ricardo Marín Viadel *, Joaquín Roldán

Universidad de Granada, España

\section{DESCRIPTORES:}

Educación artística

Arte contemporáneo

Método de enseñanza

Justicia social

Artes visuales

\begin{abstract}
RESUMEN:
Presentamos una de las acciones llevadas cabo en 2019 en el proyecto "BombeArte" en las escuelas primarias y secundarias de la ONGD “ACOES” en Tegucigalpa (Honduras). La acción "La clase-piedra" fue una instalación participativa en la que colaboró el alumnado (de cinco a dieciocho años) y profesorado de la escuela, unas 1.500 personas en total. El objetivo del proyecto es el desarrollo de la Educación Artística en estos centros educativos situados en contextos de riesgo de exclusión social. Nos propusimos vincular algunas de las obras escultóricas de la cultura maya de Copán con obras de arte contemporáneo propiciando un entorno de creación y aprendizaje sobre dibujo, escultura, fotografía e instalación. La A/r/tografía Social reúne cuatro dimensiones metodológicas y profesionales - artística, investigadora, educativa y social- simultáneamente. La a/r/tografía, en el contexto de la "Investigación Basada en Artes", congrega las características propias de la investigación en ciencias humanas y sociales con las cualidades distintivas de la creación artística. Los proyectos socio-educativo de educación artística pueden contribuir a imaginar un mundo mejor y a la construcción de sociedad más justas e integradoras. El ensayo visual es una modalidad de publicación académica de los resultados de investigaciones basadas en artes.
\end{abstract}

\section{KEYWORDS:}

Art Education

Contemporary art

Teaching method

Social justice

Visual arts

\begin{abstract}
:
We present one of the actions carried out in 2019 of the 'BombeArte' project in the primary and secondary schools of the NGDO 'ACOES' in Tegucigalpa (Honduras). The action 'La clase-piedra' [The stone-classroom] was a participatory installation in which the students (from five to eighteen years old) and the teachers of the school collaborated, about 1,500 people in total. The aim of this project is the development of Art Education in these schools located in contexts of risk of social exclusion. We set out to link some of the sculptures of the Mayan culture of Copán with contemporary artworks, creating an environment of making art and learning with drawings, sculptures, photography and installation. Social $\mathrm{A} / \mathrm{r} /$ tography brings together four methodological and professional dimensions (making art, research, education and social) simultaneously. $\mathrm{A} / \mathrm{r} /$ tography, in the context of 'Arts Based Research', brings together the characteristics of research in human and social sciences with the distinctive qualities of artistic creation. Socio-educational artistic projects can contribute to imagining a better world and to building fairer and more inclusive societies. The visual essay is a modality of academic publication of the results of an arts-based research.
\end{abstract}




\section{Introducción}

¿En qué medida las artes visuales y la educación artística pueden contribuir al reto de superar las desigualdades económicas, culturas y sociales, tanto de las personas como de los grupos y colectivos, y por lo tanto contribuir a la creación de un mundo mejor, más justo e integrador, para todas las personas? Esta ha sido una pregunta que se han planteado de forma explícita y en términos contemporáneos, desde la Ilustración hasta la actualidad (Egbert, 1981), tanto artistas, tales como León Tolstoy (1978), William Morris (1977) o Joseph Beuys (1995), como educadores y educadoras como Viktor Lowenfeld (1957) o Ana Mae Barbosa (2017), así como desde la crítica de arte, entre quienes destacan Herbert Read (1969) o Claire Bishop (2014). Por lo tanto, la densidad y la profunda elaboración de los conceptos, ideas, imágenes y proyectos artísticos y educativos que se han desarrollado a lo largo de los dos últimos siglos sobre el tema es fascinante, alumbrando utopías artísticas y sociales de muy diversa índole, que son fuente de inspiración necesaria para continuar elaborando nuevas propuestas (Marín Viadel, 2003).

El interés del tema no ha decaído porque nuestras sociedades siguen siendo radicalmente injustas. Por lo tanto, la pregunta de cómo podemos contribuir a través de la educación en general, y de la Educación Artística en particular, a una mayor justicia social sigue siendo pertinente.

Nuestro objetivo es presentar una propuesta de intervención socio-educativa inspirada en el arte contemporáneo, especialmente diseñada para contextos escolares en riesgos de exclusión social (Figuras 1 y 2).

Figura 1

Pupitre y piedra

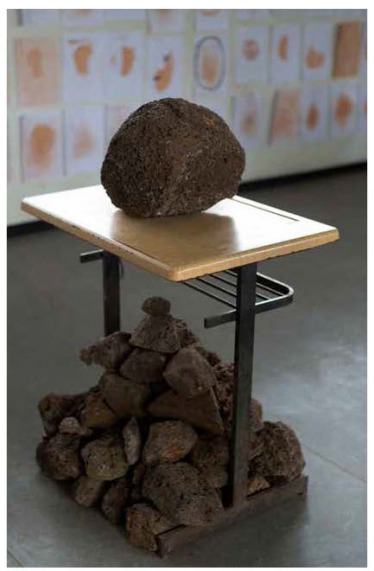

Nota. Fotografía de los autores.

Figura 2

Alumna dibujando su calavera de arcilla a partir de Copán
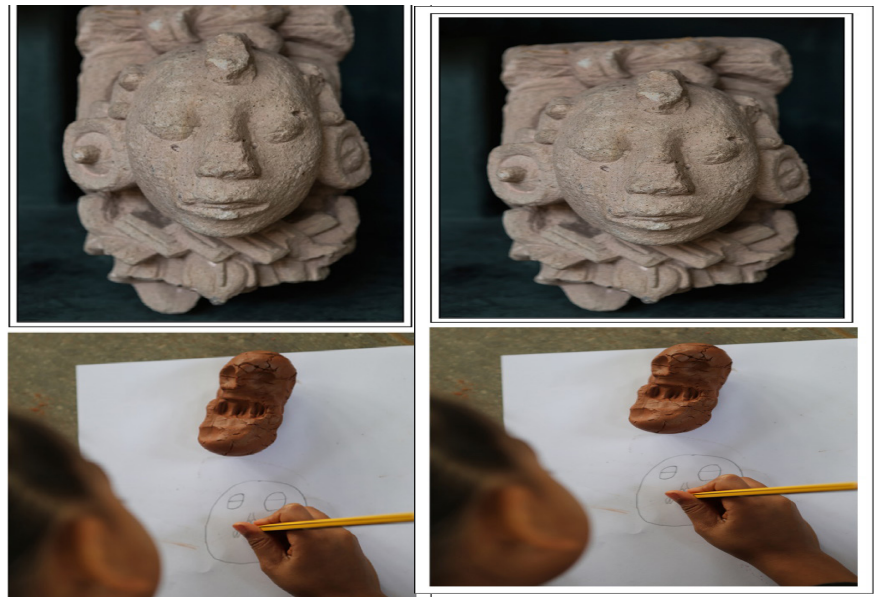

Nota. Fotografía de los autores y en la izquierda cita visual (Anónimo Maya, 426-822 a). 


\section{Método}

Un proyecto o acción a/r/tográfica tiene que involucrar necesaria y equilibradamente tres componentes: la creación artística contemporánea, la investigación científica tal y como se practica actualmente en ciencias humanas y sociales, y la educación o la enseñanza en cualquier contexto, ya sea escolar o social (Irwin y de Cosson, 2004). Una de las grandes innovaciones de la metodología a/r/tográfica es afirmar que crear, investigar y educar no son tres actuaciones profesionales absolutamente y radicalmente diferenciadas entre sí, sino que pueden entrelazarse armónicamente. El término "a/r/tografía" ideado por Rita Irwin es un acróstico que corresponde a las iniciales de tres palabras inglesas artist, researcher y teacher (http://artography.edcp.educ.ubc.ca).

En la actualidad las ciencias humanas y sociales disfrutan de una pluralidad de juegos metodológicos. Elliot Eisner (2002) vislumbró la posibilidad de vincular la investigación educativa con la creación artística, y por su parte el mundo artístico se ha abierto a tendencias, tales como el "Arte Comunitario", el "Arte participativo", o el "Artivismo", haciendo coincidir la creación artística con las reivindicaciones y trasformaciones sociales que responden a las necesidades de comunidades y grupos humanos.

Una de las consecuencias más notorias de la "Investigación Basada en Artes" y por lo tanto también de los enfoques a/r/tográficos que se acogen a este paradigma metodológico, ha sido el reconocimiento académico de una pluralidad de lenguajes y modos de representación de los datos, los procesos y las conclusiones de una indagación educativa. El resultado de un proyecto a/r/tográfico se publica tanto a través de textos escritos (incluidos los textos poéticos o los diálogos teatrales) como a través de imágenes visuales: fotografías, fotoensayos, performances y vídeos (Marín Viadel y Roldán, 2017)

Los antecedentes de esta simbiosis entre arte, investigación y educación que propugna la a/r/tografía nos permite redescubrir un buen número de artistas que han dedicado algunas de sus obras más relevantes a temas educativos y a la infancia. Por ejemplo, una pequeña y deliciosa pintura de Francisco de Goya, quien dedicó varios cuadros y grabados a retratar los juegos y diversiones infantiles, y también a presentar (como en su Capricho titulado: ¿Si sabrá más el discípulo?) una certera y clarividente visión crítica

Figura 3

Rita Irwin y tres antecedentes $a / r /$ tográficos

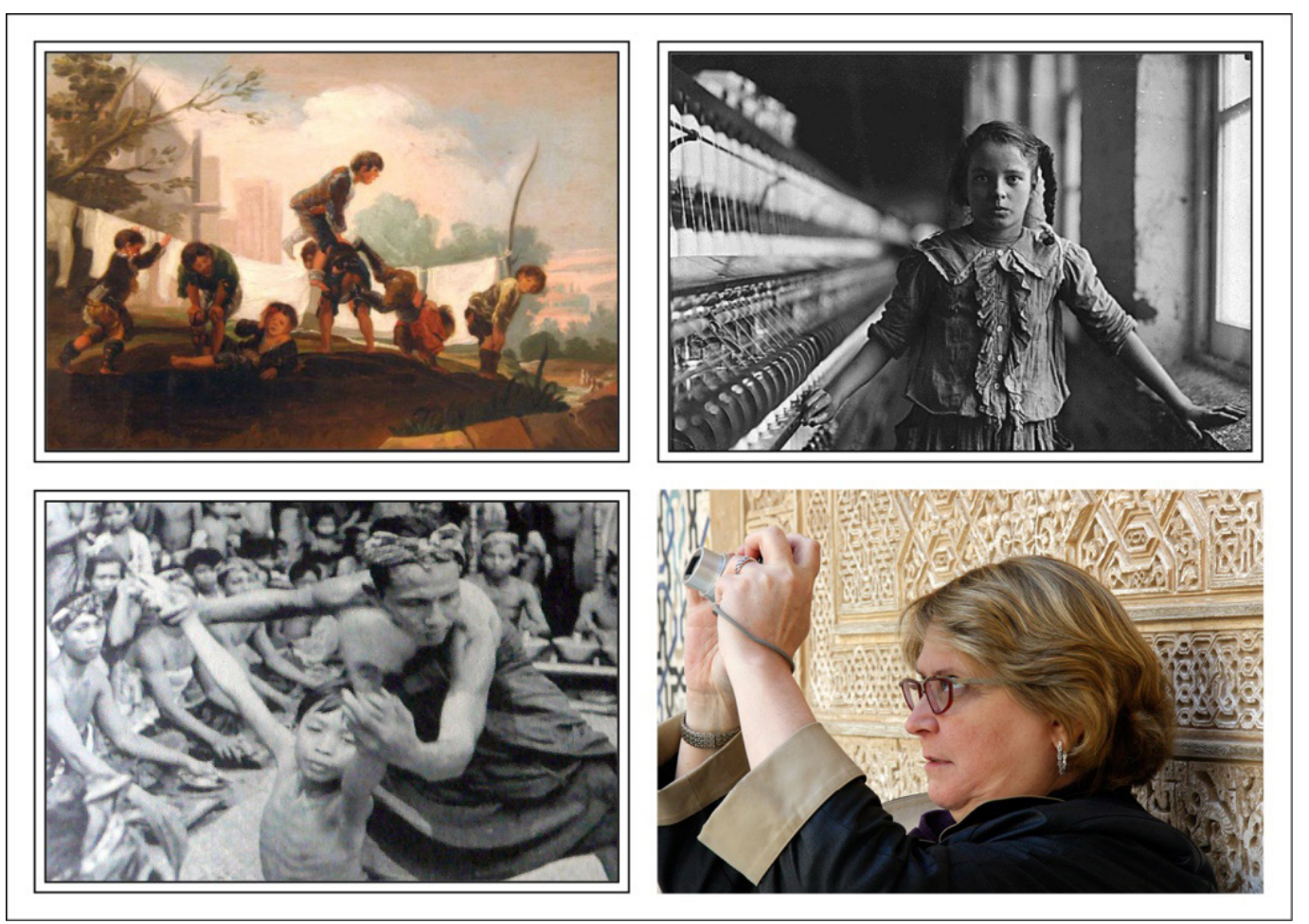

Nota. Fotografía de los autores y tres citas visuales arriba izquierda (Goya, 1788), arriba derecha (Hine, 1903) y abajo izquierda (Bateson y Mead, 1942). 
de la educación de su época desde la perspectiva del pensamiento de la Ilustración. O a Lewis W. Hine (1908), uno de los grandes fotógrafos del siglo XX, que estudió y ejerció como maestro y obtuvo un máster en educación, y que probablemente debido a su formación pedagógica se dedicó a fotografiar sistemáticamente las escuelas urbanas y rurales y sobre todo a la infancia explotada en minas y fábricas textiles. $\mathrm{O}$ el libro de Margaret Mead y Gregory Bateson (1942) sobre la cultura balinesa que usó sistemáticamente la fotografía como instrumento de investigación antropológica. ¿De qué otro modo podía dar cuenta de las estrategias de enseñanza para que las niñas y niños aprendieran los estrictos rituales, pasos, movimientos, ritmos y posiciones de las manos y de los pies, característicos de las refinadas danzas tradicionales de la cultura de Bali? (Figura 3).

Una de las obras de teatro más influyentes de la segunda mitad del siglo XX, "La clase muerta" del multifacético director de teatro, actor y pintor polaco Tadeusz Kantor (2010), que fue estrenada en 1975, usa como metáfora de la sociedad una clase escolar. En esta obra teatral, el alumnado está representado por personajes adultos, la mayoría desdoblados en muñecos y aparatos adheridos al vestuario de cada actor, que sentados en pupitres, y que, en sus gestos y desplazamientos, así como en sus escasos diálogos verbales acentúan grotescamente los modos habituales de la cultura escolar. Por último, en esta apretada síntesis de obras artísticas centradas en el mundo escolar como metáfora social, mencionaremos a Tomoko Sawada (2006), fotógrafa feminista japonesa que publicó en 2006 un foto-libro titulado School days. En cada una de las páginas del libro hay una fotografía que reproduce el prototipo de retrato escolar del grupo de alumnado de cada clase y curso. En el patio de la escuela, las alumnas, perfectamente uniformadas, están organizadas en filas horizontales, las primeras sentadas y las más altas detrás de pie, con su profesora en un extremo. Cada fotografía muestra suficientes indicios (por ejemplo, el nítido recorte de cada figura humana o la ausencia de sombras en el primer plano) para que se reconozca una intensa elaboración de posproducción, que es la clave de este retrato de grupo. Todos los rostros, incluido el de la profesora son autorretratos de la artista, con diferentes peinados y expresiones faciales (Figura 4).

Figura 4

Dos antecedentes contemporáneos de la metodología a/r/tográfica
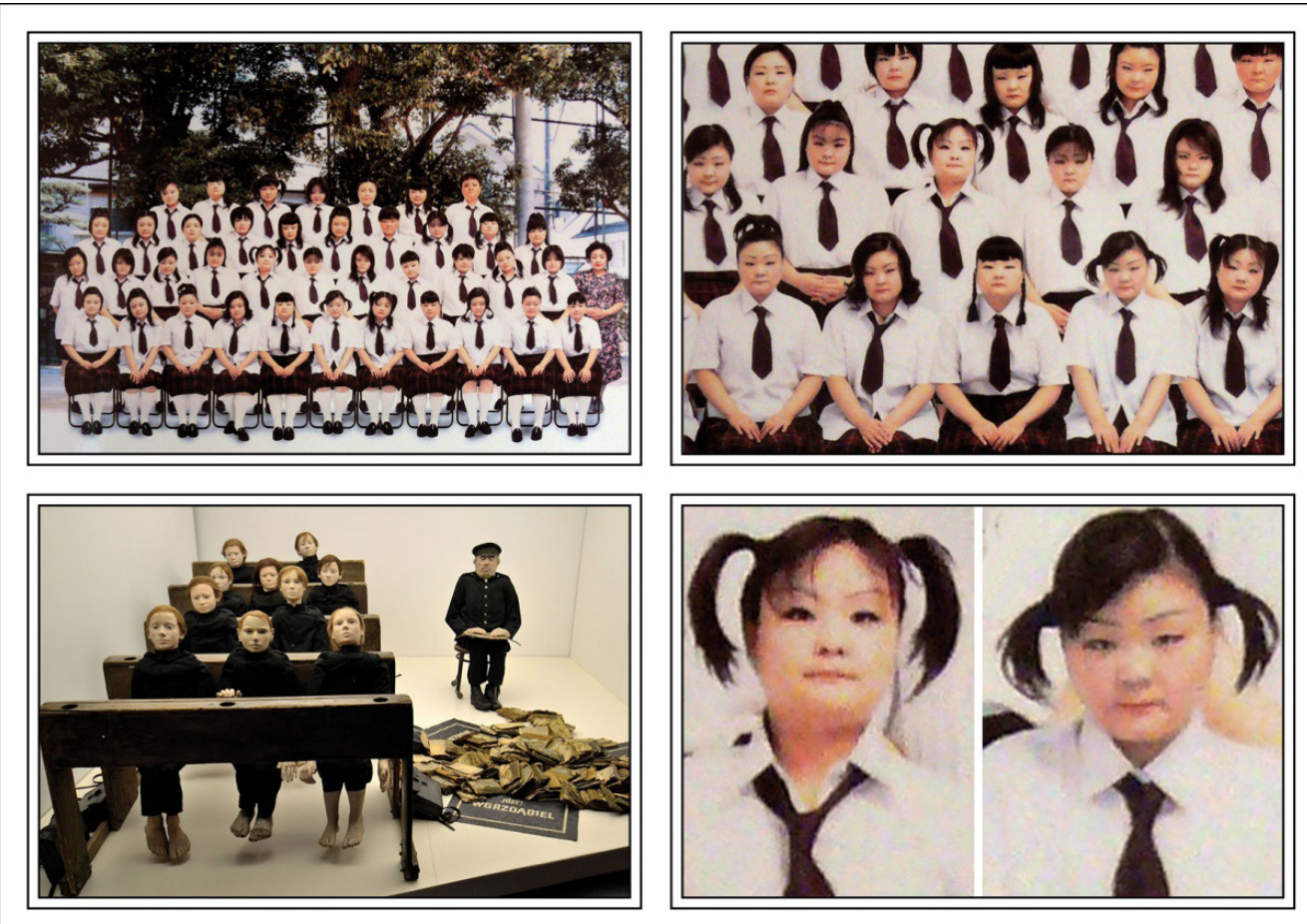

Nota. Colección de cuatro citas visuales fragmento, arriba y abajo derecha (Sawada, 2006) y abajo derecha (Kantor, 2010). 


\section{La "Clase-piedra": Una instalación a/r/tográfica}

Esta instalación colaborativa se realizó durante el mes de agosto de 2019 en la escuela primaria y secundaria Santa Teresa de la Organización No Gubernamental para el Desarrollo "Asociación Colaboración y Esfuerzo" (ACOES), situada en el barrio Nueva Capital, en la periferia de la ciudad de Tegucigalpa (https://acoes.org).

La educación es el principal objetivo de ACOES y por consiguiente sus principales actuaciones son la creación de escuelas para la infancia y la juventud excluidas del sistema público de educación en Honduras. Debido al contexto social en el que están situados estos centros educativos resulta necesario que prácticamente la totalidad de los distintos servicios públicos, -que en los países del primer mundo corresponde a diferentes administraciones-, tengan que ser asumidos por la escuela; no solo la educación propiamente dicha, sino también la alimentación, la sanidad, la seguridad (las escuelas son un espacio libre de violencia) y entre ellos, la creación artística contemporánea.

El proyecto "BombeArte" que se viene desarrollando desde 2015, está dedicado específicamente a la educación artística y al arte contemporáneo en las escuelas de ACOES. (http://bombearte.blogspot.com). Una de las acciones del proyecto "BombeArte" consiste en transformar una de las aulas de la escuela, durante aproximadamente un mes al año, en una galería de arte contemporáneo. Este es un objetivo relevante para un proyecto de Educación Artística cuando se trabaja en un contexto social en el que no existen ni museos ni galerías de arte ni centros culturales en la zona y, por lo tanto, la población escolar no tiene acceso a experiencias educativas en este tipo de instituciones.

Algunas veces esta exposición anual en las escuelas de ACOES se organiza como una instalación participativa, pensada específicamente para espacios escolares (aunque también podría reproducirse en otros contextos), y cuyo propósito es crear un entorno que provoque la reflexión sobre los problemas educativos.

A este tipo de instalaciones las hemos denominado "CITAS" (la Clase como Instalación para Transformar el Aprendizaje y la Sociedad) y en inglés "Classroom Installations for Thinking in Education and Society" (CITES) (Figura 5). CITAS es una acción artística, educativa e investigadora que combina los conceptos artísticos de "Arte Participativo" e "Instalación" con los conceptos educativos de "Aprendizaje Participativo" e "Investigación-Acción Participativa”, junto con la metodología "A/r/tográfica”.

Figura 5

Alumno en la exposición de la "Clase-piedra"

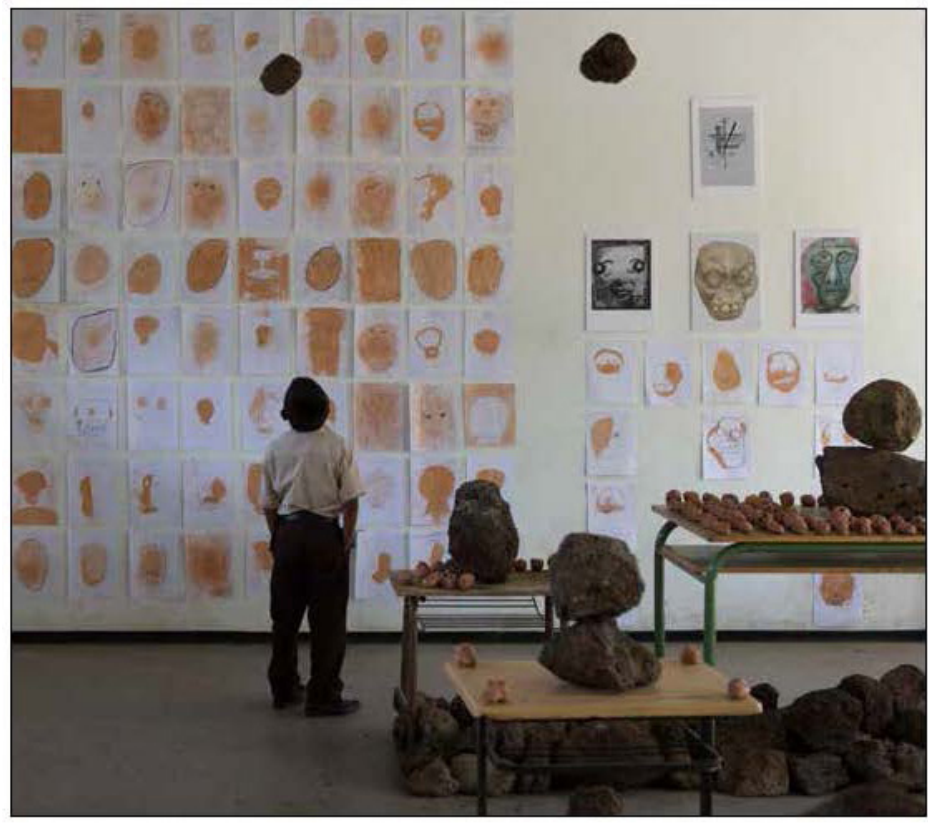

Nota. Fotografía de los autores que incluye cuatro citas visuales en la zona superior derecha, arriba (Kandinsky, 2003); abajo, de izquierda a derecha (Anónimo Maya, 426-822 b; Gordillo 1968; Picasso, 1972). 
CITAS es una instalación porque cumple con los principales rasgos definitorios de este tipo de modalidad artística contemporánea: es una construcción, con materiales variados, de grandes dimensiones, diseñada para un lugar específico y que no tiene un carácter permanente, sino que tiene lugar durante un breve período de tiempo (TATE, s. f.). De acuerdo con el artista Allan Kaprow (1965), que fue uno de los iniciadores de los hapennings y de las instalaciones como modalidades de creación artística a principios de los años sesenta del siglo XX, una de las principales características definitorias de una instalación es que ocupa todo el espacio de la sala de exposiciones. Una instalación no es un conjunto de obras artísticas independientes entre sí, como es lo habitual en una exposición de pintura y escultura que presenta un grupo de cuadros, de esculturas o de fotografías, sino que debe ser una experiencia unificada y completa para producir un gran impacto visual a través de un entorno en el que necesariamente las personas visitantes quedan inmersas.

CITAS, en su propia denominación, indica que en este tipo de instalaciones se usan referencias literales a obras de arte, tanto antiguo como contemporáneo, y estas obras deben de funcionar como elementos decisivos de la creación artística colectiva que va a tener lugar. Nosotros usamos copias o reproducciones de dibujos, fotografías y esculturas claves del arte del siglo XX, que sitúan y definen el problema artístico en torno al cual se desarrolla la instalación. Su funcionamiento visual en el conjunto es semejante a la función que cumplen las citas en un texto académico de investigación.

CITAS es una creación artística para un lugar específico: el espacio escolar. Richard Serra (1994) es el escultor norteamericano que propuso en los años setenta del siglo XX el concepto de site specific art. Este concepto ha sido decisivo para la escultura y las intervenciones artísticas contemporáneas en el espacio público. La obra de arte no es un objeto independiente del espacio en el que se sitúa, sino que se integra en dicho espacio de tal manera que el contexto (ya sean los edificios de la calle, o el mobiliario de un aula) se incorpora a la intervención artística.

CITAS es una obra de "arte participativo" porque no está físicamente hechas por un artista sino que es el público o visitantes quienes construyes la pieza final. Existen muchas modalidades diferentes de Arte Participativo, pero en cualquier caso el criterio fundamental es superar la dicotomía entre artista y público, pasando el público a ser una parte decisiva del proceso creativo (Bishop, 2014).

CITAS es “Aprendizaje y Acción Participativos (APA)", que es una metodología que proviene del trabajo social y que suele desarrollarse específicamente en áreas rurales. Sarah Thomas (s. f.) la define como un enfoque para aprender y relacionarse con las comunidades, en el que se combinan un conjunto de técnicas propias de los métodos participativos y visuales con debates y entrevistas, que facilitan el proceso de análisis y aprendizaje colectivo para incentivar la participación activa de las comunidades en las

que se desarrolla. La idea principal de la "Investigación-Acción Participativa" es comprender el mundo tratando de cambiarlo. Este concepto se ajusta perfectamente a las acciones artísticas colaborativas. Cuando creamos imágenes visuales o cuando hacemos una instalación participativa en un espacio público estamos cambiando el mundo, porque

las intervenciones artísticas son una reorganización visual del entorno que lo amplifica y transforma. La "Clase-piedra" fue una acción a/r/tográfica que tomó como referencia principal el patrimonio arqueológico de la cultura maya de Copán y en la que trabajamos con tres tipos de materiales: la piedra, el dibujo sobre papel y el espacio y mobiliario escolar. El conjunto del alumnado y profesorado de la escuela participó en la instalación, aproximadamente unas 1.500 personas. Cada grupo de estudiantes (de 30 a 35 personas) intervino varias veces en la instalación. El proceso de elaboración dura unas dos semanas para que cada grupo pueda participar en diferentes partes y fases de la instalación. Como en esta escuela hay cursos que corresponden desde los cinco y seis años de edad hasta el final del bachillerato, entre diecisiete y dieciocho años, hay que prever adaptaciones de cada una de las acciones a cada grupo de edad.

Cada clase acudía a la instalación con su profesor o profesora en sesiones de unos 45 minutos, la asignación de tiempo habitual para el desarrollo de una asignatura en el horario escolar diario.

El proceso comienza con un breve diálogo general sobre la propuesta. La pregunta es ¿qué está sucediendo aquí? El alumnado observa lo que ha ocurrido en el aula, especialmente las citas o referencias visuales que orientan la instalación y nos permiten situar el problema artístico sobre el que vamos a trabajar. Este diálogo inicial es un momento decisivo para que cada persona comprenda la idea general de la propuesta, 
para que aprenda a apreciar el valor y el interés de todo lo que sus compañeros y compañeras ya han hecho previamente, y para que sea capaz de integrar sus propias acciones en la propuesta colectiva de una forma respetuosa y coherente con el conjunto. A continuación, se comparten los conocimientos que tiene el grupo sobre la cultura de maya de Copán, debatiendo a partir de las reproducciones fotográficas de esculturas de cabezas y cráneos humanos tallados en piedra, procedentes de este enclave arqueológico. La última parte del diálogo introductorio versa sobre las relaciones entre la escultura maya con las obras de arte contemporáneo que se han seleccionado.

A continuación, subdivididos en grupos de entre seis a ocho personas, se comienza a trabajar con las piedras, con la arcilla y a dibujar individualmente sobre papel (Figura 6).

\section{Figura 6}

\section{Dibujando una calavera de Copán}

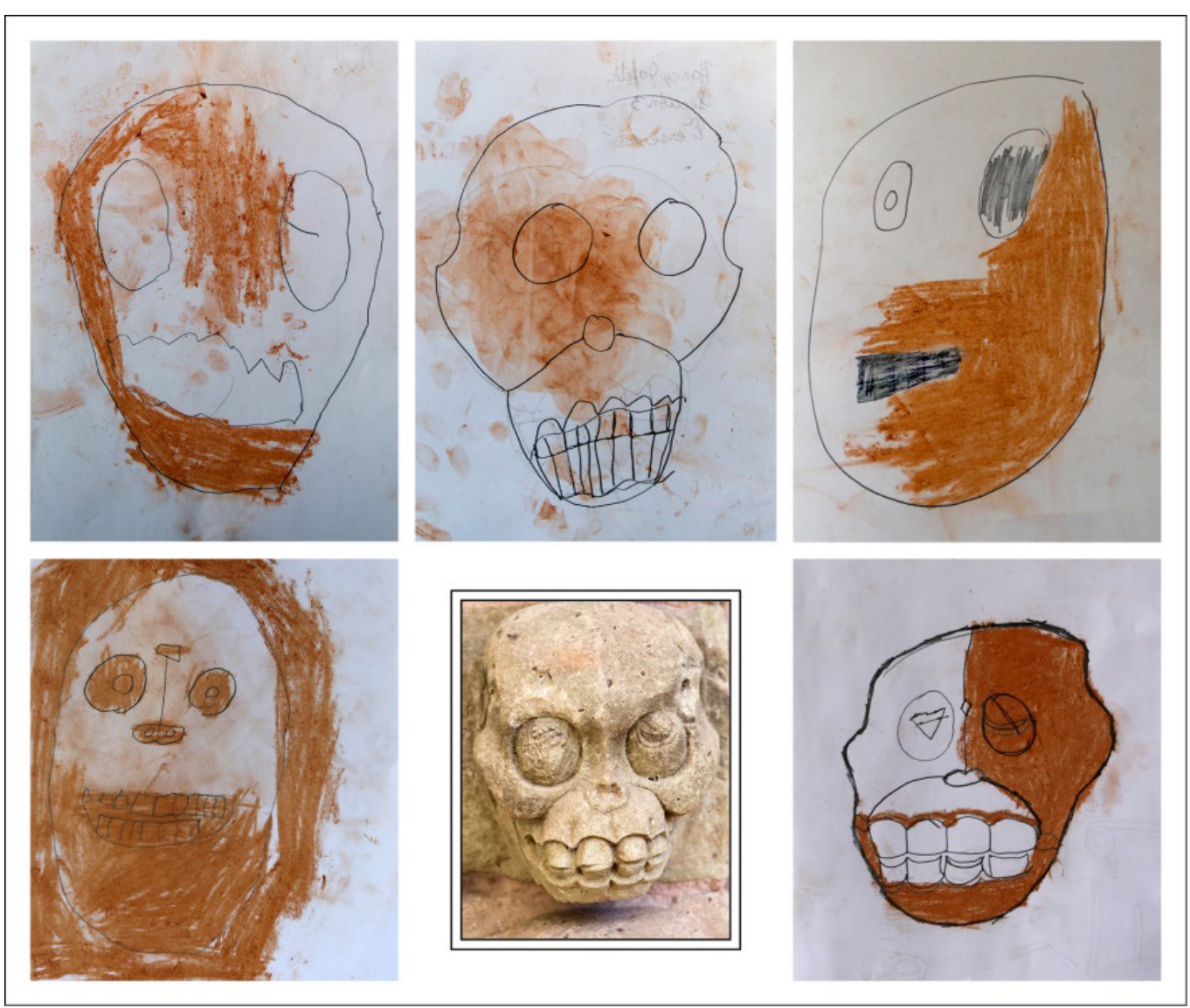

Nota. Cinco dibujos del alumnado de la escuela Santa Teresa de la ONGD “ACOES” en Tegucigalpa, todos ellos grafito y arcilla seca sobre papel, 27 ” x $21 \mathrm{~cm}$ y abajo en el centro una cita visual indirecta (Anónimo Maya, 426-822 b).

Afortunadamente los edificios de la escuela están situados en un amplio solar de la montaña con muchas piedras volcánicas de diferentes tamaños. La acción consistió en localizar piedras del tamaño aproximado de una cabeza humana y que respondiera lo más aproximadamente posible, por su forma y proporciones, a una configuración antropomorfa. Una vez en el aula-taller-sala de exposiciones, había que decidir dónde y cómo colocar cada piedra según su tamaño, color y configuración: bien encima del pupitre, bien sola en el suelo, o bien en combinaciones de dos o más piedras, formando pequeñas pirámides debajo de las mesas o colgándola de un hilo transparente para que flotaran en el aire.

La escultura maya que más llamó la atención del alumnado fue un rotundo altorrelieve de una calavera dentada que forma parte de una gradería con calaveras que se expone en el museo de la escultura de Copán. Además de trabajar con piedras el alumnado modeló con arcilla una calavera maciza, no más grande que el tamaño de su puño y dibujaba esa misma pieza, con grafito y pequeños trozos de arcilla seca que machan el papel con un intenso color ocre (Figura 7). Los centenares de dibujos fueron tapizando las 
paredes del aula, prácticamente desde el suelo hasta el marco superior de las ventanas y una selección de las pequeñas calaveras de arcilla se ordenó sobre los pupitres y mesas de la clase, bien en filas o bien alrededor de las cabezas-piedra (Figura 7).

\section{Figura 7}

Cabezas de piedra

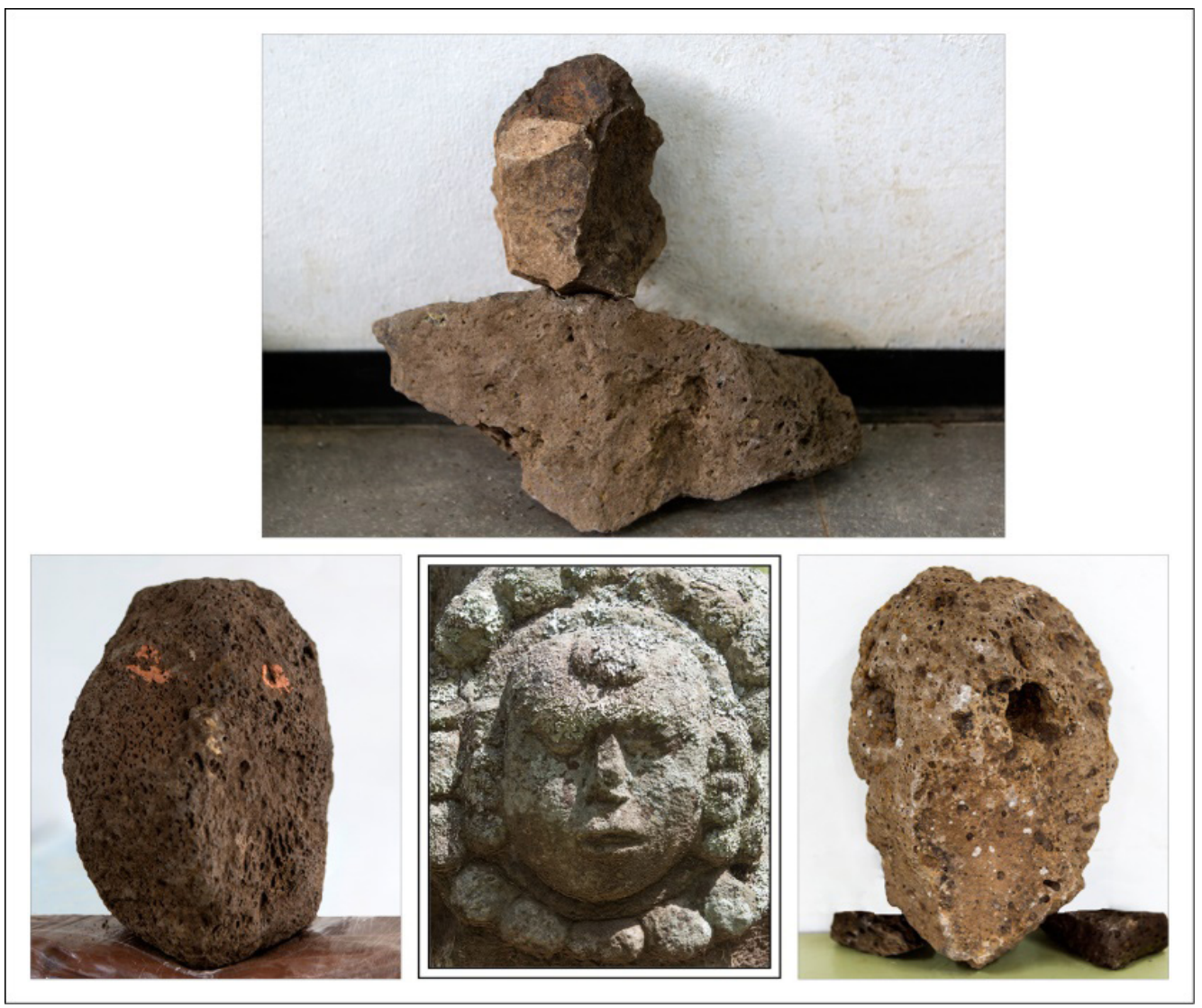

Nota. Tres cabezas antropomorfas seleccionadas e intervenidas por el alumnado de la escuela Santa Teresa de la ONGD “ACOES” de Tegucigalpa, piedra, 50 × 30 × $25 \mathrm{~cm}$. aproximadamente cada una y centro abajo, cita visual indirecta (Anónimo Maya, $426-822 \mathrm{c})$.

Varios conceptos artísticos se pusieron en juego en la instalación: descontextualización, acumulación, respeto por las cualidades propias del material, alusión e interpretación de imágenes previas, metáfora y representación. La instalación iba modificándose a medida que se acumulaban las piedras y los dibujos, en ocasiones densificándose con más y más elementos, otras suprimiendo y reorganizándolos de diversas maneras hasta lograr una imagen adecuada de un aula escolar petrificada. Al cabo de pocos días, un pequeño grupo de estudiantes, los que demostraban mayor interés en la instalación, asumió las funciones de documentación fotográfica del proceso y de organización del conjunto. Como la escuela funciona con dos grupos de alumnado, el de la mañana de siete a doce y el de la tarde de doce a cinco y media, este grupo de alumnado más interesado podía asistir a sus clases por la mañana y responsabilizarse de la instalación por las tardes o viceversa.

Los dibujos, algunos de los cuales se reproducen literalmente, no son exactamente dibujos espontáneos infantiles (Figura 8). En primer lugar, porque a todos se les propuso dibujar del natural, o bien las calaveras que ellos mismos habían modelado, o bien las reproducciones fotográficas de las esculturas de Copán; y, en segundo lugar, porque se hizo especial énfasis en usar los trocitos de arcilla seca, no para rellenar de color toda la figura que habían dibujado con grafito (que es la tendencia habitual sobre todo del alumnado de menor edad) sino únicamente para resaltar el volumen de las piezas escultóricas en las que se estaban basando. 
Cuando la instalación quedó concluida comenzaron las visitas para disfrutar del resultado final (Figura 8). Siguiendo el protocolo habitual de las visitas a una exposición de arte contemporáneo, un equipo de mediadores y mediadoras, compuesto por alumnado del centro especialmente interesado en las artes visuales, organizaba el recorrido y proponía actividades para reforzar la contemplación y el disfrute de la instalación. Como en la visitas a cualquier museo o exposición se producían recorridos individuales o en grupo. Como los visitantes habían sido protagonistas y creadores de la instalación disfrutaban buscando la piedra que había seleccionado o su dibujo expuesto en las paredes, pero sobre todo se sorprendían ante el esplendor visual del resultado final que habían conseguido entre todos y todas.

Figura 8

Alumnado visitando la exposición / instalación

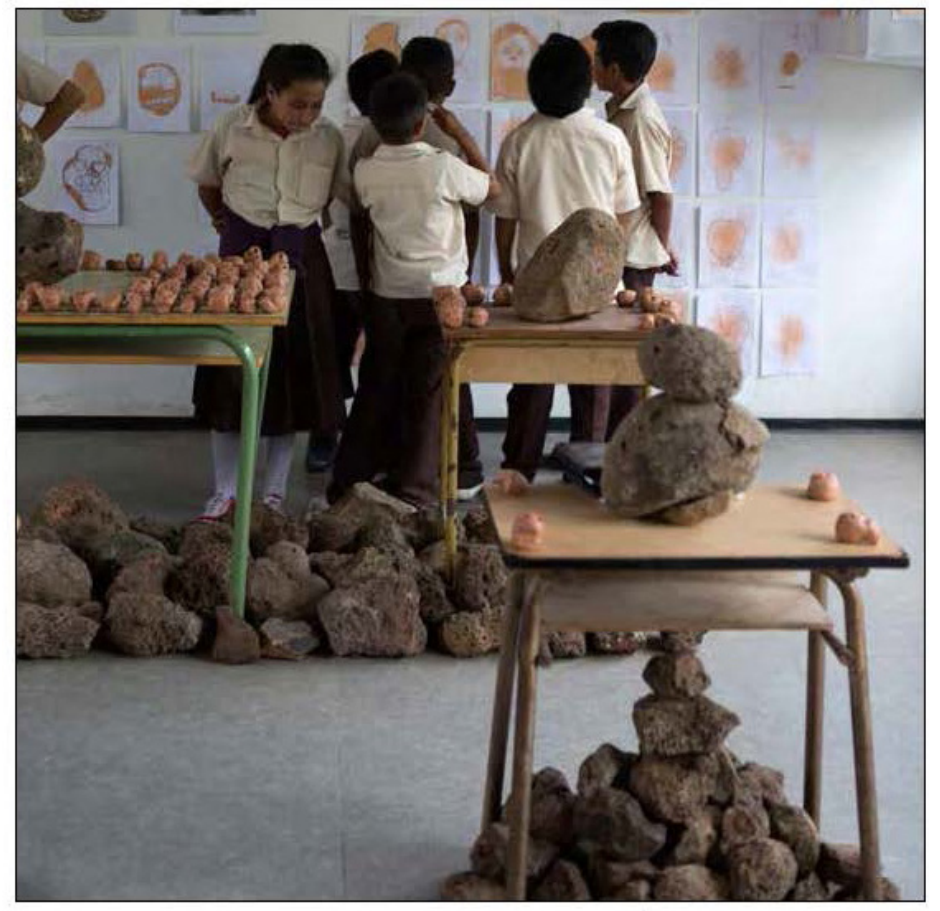

Nota. Fotografía de los autores.

\section{Discusión}

La necesidad y eficacia de las intervenciones artísticas en comunidades en riesgo de exclusión social y su contribución al desarrollo y a la justicia social han sido fundamentadas en los últimos años (Bell y Desai, 2011; Escaño, 2019) y desde hace algo más de una década se acuñó el término específico "Social Justice Art Education" (Dewhurst, 2010 y 2014). En el marco de este contexto, los principales hallazgos de la "Clase-piedra" como indagación a/r/tográfica corresponden a los cuatro ámbitos -educativo, artístico, investigador y social- definitorios de este enfoque metodológico.

El desarrollo de esta instalación permitió combinar secuencias de aprendizaje tanto individual como colectivo porque cada participante dibujaba y modelaba en arcilla sus piezas personales, mientras que la selección de las piedras/cabezas aproximadamente antropomórficas y su distribución por el espacio de la instalación se realizaron en grupos de cuatro a cinco personas. Pudimos comprobar la validez de partir de referentes visuales específicos -reproducciones fotográficas impresas de alta calidad de las esculturas mayas y de pinturas y dibujos de arte contemporáneo situadas en el centro de las cuatro paredes del aulapara que estas imágenes fuesen las que organizaran, desde el principio, el desarrollo de la instalación. El uso visualmente preferencial de los referentes tanto antiguos como contemporáneos provocó un triple efecto. Por un lado, estimuló la rápida identificación de los participantes con imágenes clave de su propio patrimonio cultural; por otro, facilitó el descubrimiento de las correspondencias entre obras de arte de 
diferentes épocas y culturas; y por otro, resultó extraordinariamente motivador entremezclar cuidadosamente las propias creaciones visuales de los participantes con las grandes obras de arte que estaban presentes en la instalación, aunque se tratase de reproducciones y no de originales.

\section{Conclusiones}

Aunque a menudo se considera que el único criterio para hablar de un proyecto artístico-educativo sobre justicia social es que el tema esté directa y explícitamente conectado con los debates sociopolíticos más urgentes (migración, xenofobia, sexismo, etc.), la educadora artística Marit Dewhurst (2010, p. 8) sostiene que: "si el proceso de creación de arte ofrece a los participantes una forma de construir conocimiento, analizar críticamente una idea y actuar en el mundo, entonces están participando en una práctica de creación de arte para la justicia social”. Por lo tanto, no es tanto la temática que aborda una acción artística/educativa como el modo de enfocarla y desarrollarla lo que la sitúa en el terreno de arte para la justicia social. La instalación la "Clase-piedra" proponía un tema abiertamente educativo: un aula escolar y sus pobladores naturales (profesorado y alumnado). La representación del paisaje escolar y las personas que lo configuran, en la propia escuela, quedó marcada por las posibilidades que ofrecía el principal material que intervenía en la instalación: las piedras. El aula que acogió la instalación nunca dejó de ser un aula, ni la instalación pretendió disimular su condición o transmutarla en una galería de arte; más bien se trataba de construir una nueva imagen sobre el hecho educativo, ligeramente desconcertante.

\section{Agradecimientos}

Este artículo es uno de los resultados del Proyecto I+D+i del Ministerio de Ciencia e Innovación, Gobierno de España, Ref.: PID2019-109990RB-I00. "Metodologías de intervención social basadas en artes visuales: creación cultural, educación, inclusión y patrimonio".

\section{Referencias}

Anónimo Maya. (c. 426-822 a). Piedra, $38 \times 22 \times 30 \mathrm{~cm}$. aproximadamente [Cabeza]. Museo de la escultura de Copán.

Anónimo Maya. (c. 426-822 b). Gradería con calaveras de la estructura 16. Altorrelieve de piedra, $20 \times 20 \times 10 \mathrm{~cm}$. aproximadamente [Calavera]. Museo de la escultura de Copán.

Anónimo Maya. (c. 426-822 c). Piedra, $15 \times 15 \times 7 \mathrm{~cm}$. aproximadamente [Detalle de cabeza en un mascarón zoomorfo]. Parque Arqueológico.

Bateson, G. y Mead, M. (1942). Balinese character, a photographic analysis. The New York Academy of Sciences.

Barbosa, A. M. (2017). Redesenhando o desenho: educadores, politica e história. Cortez.

Bell, L. A. y Desai, D. (2011). Imagining otherwise: Connecting the arts and social justice to envision and act for change. Equity \& Excellence in Education, 44(3), 287-295. https://doi.org/10.1080/10665684.2011 591672

Beuys, J. (1995). Cada hombre un artista. Visor.

Bishop, C. (2014). Infiernos artificiales. Arte participativo y políticas de la espectaduría. TEE.

Dewhurst, M. (2010). An inevitable question: Exploring the defining features of social justice art education. Art Education, 63(5), 7-13. https://doi.org/10.1080/00043125.2010.11519082

Dewhurst, M. (2014). Social justice art. A framework for activist art pedagogy. Harvard Education.

Egbert, D. D. (1981). El arte y la izquierda en Europa. De la revolución francesa a mayo de 1968. Gutavo Gili.

Eisner, E. (2002). The arts and the creation of mind. Yale University Press.

Escaño, C. (2019). Lo que no se ve no existe. Artes, imagen y educación para el desarrollo. UNED. 
Gordillo, L. (1968). Serie blanda A. (Fotografía y técnica mixta en bolsas de plástico sobre lienzo] Museo Nacional Centro de Arte Reina Sofía.

Goya, F. (1788). Niños saltando a pídola [Óleo sobre lienzo]. Real Academia de Bellas Artes de San Fernando.

Hine, L. W. (1903). One of the spinners in Whitnel Cotton Mfg. Co. N.C. [Impresión fotográfica]. Library of Congress.

Irwin, R. L. y De Cosson, A. (2004). A/r/tography: Rendering self through arts-based living inquiry Pacific Educational Press.

Kandisnky, V. (2003). Ilustración 24. Estructura horizontal-vertical con diagonal antagónica y tensiones de puntos. Esquema del cuadro “Intime Mitteilung”. En V. Kandinsky, Punto y línea sobre el plano (p. 156). Paidós.

Kantor, T. (2010). La clase muerta. Alba.

Kaprow, A. (1965). Enviroments, assemblages and happenings. Harry N. Abrams.

Liamputtong, P. y Rumbold, J. (2008). Knowing differently: Arts-based and collaborative research methods. Nova Science.

Lowenfeld, V. (1957). Creative and mental growth. MacMillan.

Marín Viadel, R. (2003). Utopías visuales y educativas. En R. Marín Viadel (Coord.) Didáctica de la educación artística (pp. 499-541). Pearson.

Marín Viadel, R. y Roldán, J. (2017). Ideas visuales. Investigación basada en artes e investigación artística. Universidad de Granada.

Morris, W. (1977). Arte y sociedad industrial. Fernando Torres.

Picasso, P. (1972). Autorretrato [Lápiz y ceras de colores sobre papel]. Colección particular.

Read, H. (1969). Educación por el arte. Paidós.

Sawada, T. (2006). School days. Seigensha Art Publishing.

Serra, R. (1994). Writings / interviews. University of Chicago Press.

TATE. (s. f.). Installation art. TATE.

Thomas, S. (s. f.). What is participatory learning and action (PLA): An introduction. http://idp-key-resources.org/documents/0000/d04267/000.pdf

Tolstoy, L. (1978). La escuela de Yasnaia Poliana. José J. de Olañeta.

\section{Breve cv de los autores}

\section{Ricardo Marín Viadel}

Licenciado en Bellas Artes, Universidad de Barcelona y Doctor en Filosofía y Ciencias de la Educación, Universidad de Valencia. Ha sido profesor de las Universidades de Valencia (1980-81), Barcelona (198184) y Complutense de Madrid (1984-88). Actualmente es catedrático de Educación Artística en la Facultad de Bellas Artes de la Universidad de Granada y coordinador del programa interuniversitario de doctorado "Artes y Educación” (http://doctorados.ugr.es/arteducacion/). Publicaciones recientes: (2015) Dibujo y patrimonio: Qubbet el-Hawa, Edfú y Tesalónica (http://hdl.handle.net/10481/43991). (2017) Ideas Visuales. Investigación basada en Artes e Investigación Artística. (2017) Reivindicación de cinco piezas etruscas del Museo Arqueológico de Granada (http://hdl.handle.net/10481/48498). Email: ricardom@ugr.es

ORCID ID: https://orcid.org/0000-0001-9918-0627 


\section{Joaquín Roldán}

Licenciado y doctor en Bellas Artes por la Universidad de Granada. Escultor y Profesor Titular de Universidad de educación artística en esta universidad y coordinador del Máster oficial interuniversitario "Artes visuales y educación: un enfoque construccionista" (https://artes-visuales.org/). Ha sido investigador del Fulbright Visiting Scholar Program en el Massachusetts Institute of Technology (MIT) de Boston (USA) en 2015. Publicaciones recientes: (2012) Metodologías artísticas de investigación en educación. (2017) Ideas Visuales. Investigación basada en Artes e Investigación Artística. (2020) Aprendiendo a enseñar artes visuales. Un enfoque a/r/tográfico. (2021) Enseñanza de las Artes Visuales en contextos de riesgo de exclusión social. Email: joaquinroldan@ugr.es

ORCID ID: https://orcid.org/0000-0001-5318-6492 